\title{
PEMAHAMAN SEKOLAH TERHADAP KEBIJAKAN TENTANG PENYELENGGARAAN KURIKULUM SETARA JENDER
}

\author{
Abdul Syukur Ibrahim dan Lilik Wahyuni \\ Pendidikan Bahasa Indonesia, Universitas Negeri Malang \\ email: lilikwahyuni.bi@gmail.com
}

\begin{abstract}
Abstrak
Penyusunan dan pengembangan kurikulum harus sesuai dengan keadaan dan kebutuhan stake holder dan peserta didik dengan tetap mengacu pada standar nasional pendidikan dam kebijakan nasional lainnya. Tujuan penelitian ini adalah untuk mendapatkan deskripsi objektif tentang pemahaman sekolah terhadap UU No 20 tahun 2003, acuan operasional pengembangan kurikulum, dan ratifikasi internasional yang dibuat Indonesia.pendekatan. Penelitian ini menggunakan rancarangan penelitian survey dengan jumlah sampel 20 SD yang diperoleh dengan teknik multistages area cluster sampling. Dalam penelitian ini, peneliti berperan sebagai instrumen kunci dengan dibantu oleh angket dan pedoman wawancara.Hasil penelitian ini adalah guru dan kepala sekolah belum mempunyai pengetahuan tentang dasar kebijakan kurikulum bahasa Indonesia setara jender. Informasi yang dibutuhkan sekolah meliputi kebutuhan tantang cara pengembangan bidang studi bahasa Indonesia sebagai wahana penanaman pangarusutamaan jender, cara pengembangan bidang studi bahasa Indonesia berbasis jender sebagai wahana pembentuk karakter, dan cara memasukkan nilainilai kesetaraan jender dalam bidang studi bahasa Indonesia
\end{abstract}

Kata Kunci: pemahaman sekolah, kebijakan, penyelenggaraan, kurikulum setara jender

\begin{abstract}
The forming and development of educational curriculum must be fitted with the reality and requirements of the stakeholders and the students by keep referring to the national education standard and other national policies. This research aims to describe objectively about the school's understanding towards regulations number 20 year 2003 about references in national education curriculum development and international ratifications made by Indonesian government. This research employs survey research plan with multistage area cluster to 20 elementary school students as samples. In this research, the researcher played as the key instrument by referring to prepared questions and interview guidance. The result showed that the teachers and the principal have not got some proper understanding about the baseline of gender-equal curriculum policy in Indonesian language subject. The schools need information about ways in developing the Indonesian language subject, wether as a tool for the application of gender-equal curriculum and ways in developing gender-equal based Indonesian language study program as a media to form a positive character and ways in putting gender-equal values in Indonesian language subject.
\end{abstract}

Keywords: schools understanding, policies, curriculum forming and development, gender-equal curriculum. 


\section{Pendahuluan}

Kurikulum merupakan perangkat pembelajaran yang merepresentasikan rancangan yang menyeluruh oleh pihak sekolah yang akan diberikan kepada peserta didik dalam satu periode jenjang pendidikan untuk memperoleh hasil pembelajaran yang sudah ditentukan. Sebagai perangkat pembelajaran, kurikulum harus dirancang sesuai dengan kebutuhan penyelenggara pendidikan yang meliputi pihak sekolah, stakeholder, dan siswa.

Agar kurikulum bisa menjawab kebutuhan semua pihak, kurikulum harus selalu dingkritisi dan disesuaikan dengan perkembangan dalam masyarakat, termasuk masalah kesetaraan jender. Inspres No. 9 tahun 2000 merupakan landasan bagi seluruh komponen masyarakat untuk mengarusutamaakan kesetaraan gender dalam segala bidang, termasuk pendidikan. Perubahan kurikulum merupakan suatu langkah yang strategis untuk memikirkan kembali jenis pengetahuan yang selama ini menjadi isi kurikulum. Salah satu jenis pengetahuan yang harus dipikirkan adalah jender. Sebagai suatu bentuk kategori sosial, selama ini jender masih belum terefleksi secara proporsional dalam kurikulum. Padahal, ketidaksetaraan jender mempunyai dampak sosial yang sangat tinggi dalam masyarakat.

Ketika memasukkan nilai-nilai kesetaraan jender, banyak pihak yang mempertanyaan tentang cara memasukkan dalam kurikulum. Banyak pihak yang mempertanyakan tentang bidang studi yang bisa dijadikan induk dalam penanaman nilai-nilai kesetaraan jender. Dalam masyarakat yang berbudaya patriarki, mereka ada kekhawatiran kalau diangap menentang budaya ketika harus memasukkan nilai-nilai kesetaraan jender. Padahal, dalam acuan operasional pengembangan kurikulum sudah terjabar tentang pembelajaran yang membentuk peserta didik menjadi diri yang mengenal dirinya sebagai individu yang berbeda dengan individu lain.

Memasukkan nilai-nilai jender dimaksudkan untuk mempersiapkan peserta didik agar dapat hidup dalam masyarakat multikultural. Pengetahuan tentang kesetaraan jender perlu dimasukan dalam kurikulum karena globalisasi telah menghapus perbedaan peran sosial laki-laki dan perempuan. Kurikulum setara jender dipersiapkan untuk membentuk anak laki-laki dan perempuan yang siap menghadapi masa depan mereka yang sudah tidak membedakan arena domestik dan publik. Masyarakat sekarang lebih egaliterkarena perkembangan teknologi makin meningkatan kesadaran hak setiap orang untuk mendapatkan manfaat dari pembangunan.

Menghadapi fakta tersebut, sekolah perlu menyiapkan kurikulum yang mampu mempersiapkan peserta didik dapat secara fleksibel melakukan suatu peren-peran jender yang terbebas dari stereotipi. Peran-peran jender berbasis stereotipi yang selama ini terjadi berdampak dampak negatif yakni terjadinya kerentanan hidup terhadap perempuan sebagai pihak yang lebih termarginalkan seperti: meningkatnya kekerasan dalam rumah tangga, gizi buruk dan kematian ibu melahirkan, masalah reproduksi, feminisasi kemiskinan, dan masalah-masalah lain. Melalui pengembangan kurikulum setara jender, mereka dipersiapkan untuk dapat berperan berdasarkan kesempatan dan kebutuhan. Dengan demikian, mereka akan dapat menghargai secara setara pekerjaan rumah tangga yang tidak bernilai ekonomis dan pekerjaan yang bernilai ekonomis.

Agar pengembangan kurikulum berbasis jender bisa berjalan dengan kepentingan sekolah dan stakeholder perlu dilakukan pengkajian tentang pemahaman pihak sekolah terhadap dasar kebijakan penyelenggaraan kurikulum setara jender. Untuk menjawab persoalan tersebut, dalam artikel ini dibahas tentang pemahaman sekolah terhadap UU No. 20 tahun 2003, acuan operasional pengembangan kurikulum, dan rativikasi internasional yang dibuat Indonesia.

\section{Metode Penelitian}

Penelitian ini menggunakan rancangan penelitian survey. Target utama pene- 
litian tahap ini adalah mendapatkan informasi tentang pemahaman sekolah terhadap UU No 20 tahun 2003, acuan operasional pengembangan kurikulum, dan ratifikasi internasional yang dibuat Indonesia. Adapun langkah-langkah yang dilakukan dalam penelitian ini adalah sebagai berikut.

Populasi penelitian ini adalah Sekolah Dasar di Malang. Sekolah Dasar Malang sebanyak 1413 dengan rincian Sekolah Dasar di Kota Malang berjumlah 250 dan Sekolah Dasar di Kabupaten Malang berjumlah 1163. Karena jumlahnya besar maka diadakan penyampelan dengan menggunakan teknik multistages area cluster sampling. Area Malang dikelompokkan menjadi area utara, selatan, timur, barat, dan tengah. Yang dimasukkan area Utara, Selatan, Timur, Barat adalah area Kabupaten Malang sedangkan yang dimasukkan area Tengah adalah area Kota Malang. Masing-masing area diambil 4 SD. Dari perhitungan tersebut, jumlah keseluruhan subjek sasaran penelitian ini adalah 5 X 2 sehingga menjadi 20 SD.

Dalam penelitian ini, peneliti berperan sebagai instrumen kunci dengan dibantu oleh angket dan pedoman wawancara. Angket dan pedoman wawancara digunakan untuk mendapatkan informasi tentang: UU No. 20 tahun 2003, acuan operasional pengembangan kurikulum, dan ratifikasi internasional yang dibuat Indonesia. Ada beberapa langkah yang ditempuh dalam menyusun angket. Pertama, melakukan penjabaran variabel kurikulum bahasa Indonesia dan ideology jender. Kedua, disusun kisi-kisi instrumen. Ketiga, menyusun butir-butir pertanyaan berdasarkan kisi-kisi yang telah dibuat. Keempat, melakukan telaah butir pertanyaan dari segi substansi dan teknis administrasi. Kelima, penyempurnaan instrumen. Wawancara yang digunakan adalah wawancara mendalam. Pedoman wawancara berupa pokok-pokok pertanyaan untuk mendapatkan jawaban terbuka dari responden.

Teknik pengumpulan data yang digunakan dalam penelitian ini adalah observasi, angket, wawancara mendalam, dan focusing group discussion (FDG). Observasi, angket dan wawancara digunakan untuk mengumpulkan data tentang UU No. 20 tahun 2003, acuan operasional pengembangan kurikulum, dan ratifikasi internasional yang dibuat Indonesia. Pengisian angket akan didampingi oleh peneliti agar tingkat kesalah penelitian dapat ditekan sekecil-kecilnya dan persentase pengembalian jawaban lebih tinggi. Wawancara mendalam dilakukan secara informal. Dengan cara ini, informasi yang diperoleh akan semakin banyak, mendalam, dan menggambarkan keadaan yang sesungguhnya. FGD digunakan untuk mengumpulkan data kebutuhan masyarakat, dunia pendidikan, dan peserta didik terhadap kurikulum bahasa Indonesia berbasis jender yang bersifat spesifik, khas, dan lokal.

\section{Hasil dan Pembahasan}

\subsection{Pemahaman Sekolah terhadap UU No 20 tahun 2003 tentang Sistem Pendidikan Nasional Berkaitan dengan Penyelenggaraan Pendi- dikan Setara Jender}

Kurikulum setara jender merupakan program pemerintah yang tertuang dalam UU No. 20 tahun 2003. Dalam UU No. 20 tahun 2003 tersebut tertuang kebijakan yang menyatakan bahwa kesempatan pendidikan pada setiap kesatuan pendidikan tidak membedakan jenis kelamin, agama, ras, kedudukan sosial, dan tingkat kemampuan ekonomi dan tetap mengindahkan kekhususan satuan pendidikan yang bersangkutan. Oleh karena itu, lembaga penyelenggara pendidkan harus melakukan pembelajaran yang setara termasuk setara jender.

Meskipun sudah dinyatakan dalam bentuk undang-undang, ternyata tidak semua kepala sekolah dan guru memahami isi kebijakan tersebut. Mayoritas dari mereka mengatakan tidak mengetahui kebijakan tersebut karena belum pernah mendapat sosialisasi. Dalam menyelenggarakan pendidikan, mereka tidak bertindak proaktif dengan membaca undang-undang. Mereka 
hanya menunggu program pemerintah.

Dari angket yang sudah diisi dapat dilihat bahwa kepala sekolah banyak yang tidak mengetahui bahwa dalam UU No. 20 tahun 2003 terdapat kebijakan penyelenggaraan pendidikan setara jender. Dari kepala sekolah yang diteliti, 50\% dari responden sudah mengetahui isi UU No. 20 tahun 2003 mengenai kesempatan pendidikan pada setiap kesatuan pendidikan tidak membedakan jenis kelamin, agama, ras, kedudukan sosial, dan tingkat kemampuan ekonomi dan tetap mengindahkan kekhususan satuan pendidikan yang bersangkutan. Sedangkan $45 \%$ responden yang lain, belum mengetahui isi UU No. 22 tahun 2003 dan 5\% dari responden tidak menjawab. Pemahaman kepala sekolah tersebut dapat dilihat pada tabel berikut.

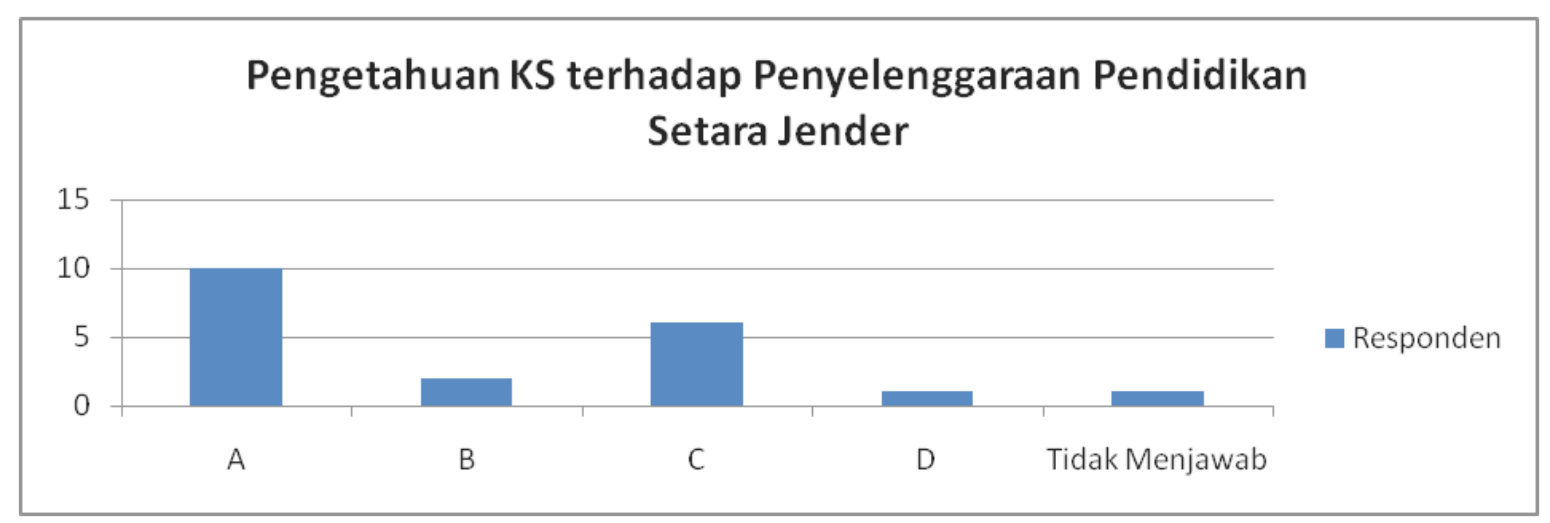

Tabel 1 Pengetahuan Kepala Sekolah terhadap Penyelenggaraan Pendidikan Setara Jender

Dari guru yang diteliti, $50 \%$ dari respondens sudah mengetahui isi UU No. 20 tahun 2003 mengenai kesempatan pendidikan pada setiap kesatuan pendidikan tidak membedakan jenis kelamin, agama, ras, kedudukan sosial, dan tingkat kemampuan ekonomi dan tetap mengindahkan kekhusu- san satuan pendidikan yang bersangkutan. Sedangkan $50 \%$ responden yang lain, belum mengetahui isi UU No. 22 tahun 2003. $10 \%$ dari responden tidak menjawab. Gambaran umum dari analisis data di atas dapat dilihat pada tabel berikut.

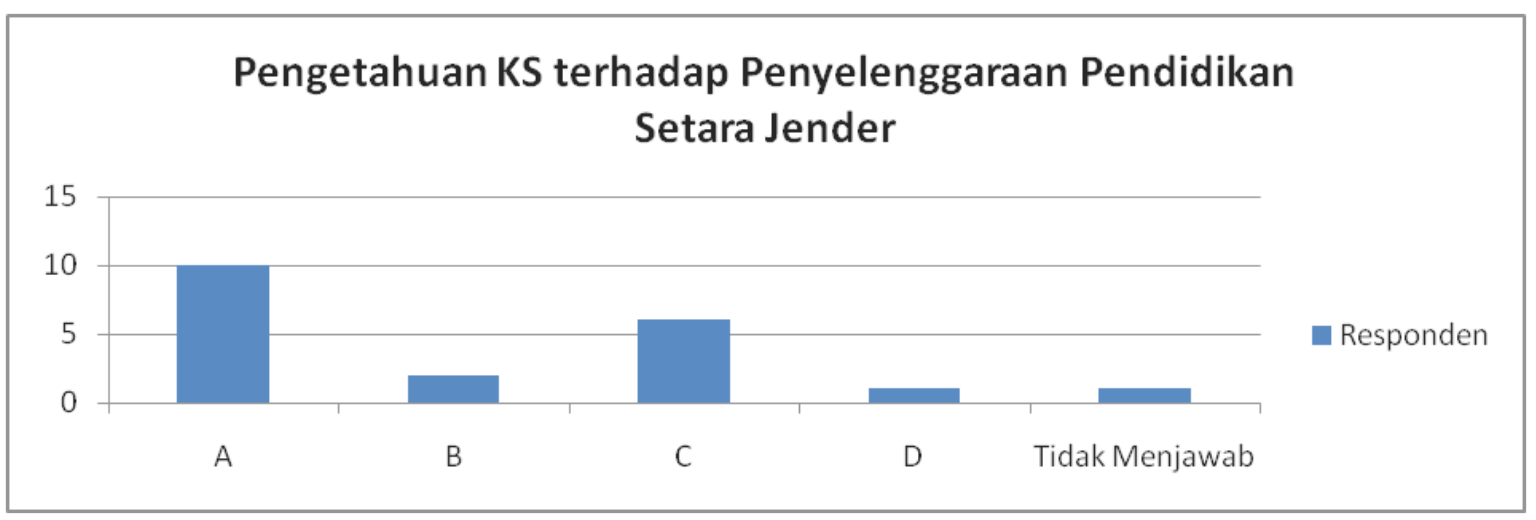

Table 2 Pengetahuan guru terhadap penyelenggaraan pendidikan setara jender

\subsection{Pemahaman Sekolah terhadap Ac- uan Operasional Pengembangan Kurikulum (AOPK)}

AOPK merupakan dasar pengemban- gan kurikulum di sekolah. Berkaitan dengan jender, AOPK mengatur bahwa kurikulum yang dikembangkan memberi akses, mendorong partisipasi, memberi perlakuan yang menggambarkan kesetaraan, dan member- 
ikan manfaat yang ama bagi peserta didik-siswi. Dalam hal ini diharapkan struktur dan muatan isi kurikulum tidak stereotipe (memberi label-label khusus). Misalnya, mulok untuk menjahit perempuan dan mulok elektronika hanya untuk laki-laki. Demikian juga bahan ajar yang dikembangkan dari tiap-tiap mata pelajaran hendaknya dapat menanamkan persepsi kesetaraan antara laki-laki dan perempuan. Misalnya, tidak menanamkan persepsi bahwa laki-laki layak menduduki jabatan tertentu, sedangkan wanita hanya cocok menduduki jabatan tertentu. Kurikulum dianggap memiliki kesetaraan jender jika tidak memberi stereotipe perempuan atau laki-laki. Pengelolaan mulok perlu membuka akses bahwa semua jenis mulok dapat dipilih oleh anak laki-laki dan perempuan.

Dalam kaitannya dengan bidang studi Bahasa Indonesia, dalam AOPK dinyatakan bahwa kurikulum Bahasa Indonesia harus ditujukan untuk pengembangan peserta didik agar mengenal dirinya sebagai individu yang berbeda dengan individu lain. Melalui pengenalan dirinya sebagai individu yang berbeda dengan individu lain diharapkan dapat tertanam persepsi kesetaraan antara laki-laki dan perempuan. Melalui cara tersebut diharapkan tidak tertanan stereotipi perempuan atau laki-laki.

Meskipun sudah tertuang dalam AOPK, tidak semua kepala sekolah dan guru mengetahui tentang perlunya pengembangan pembelajan bahasa Indonesia setara jender. Dari hasil analisis, diperoleh gambaran bahwa 55\% dari responden sudah mengetahui pernyataan "kurikulum bahasa Indonesia harus ditujukan untuk pengembangan peserta didik agar mengenal dirinya sebagai individu yang berbeda dengan individu lain" terdapat dalam acuan operasional pengembangan kurikulum. Sedangkan $40 \%$ dari responden, belum mengetahui bahwa pernyataan tersebut terdapat dalam acuan operasional pengembangan kurikulum. $5 \%$ dari responden tidak menjawab. Gambaran umum dari analisis data di atas dapat dilihat pada tabel berikut.

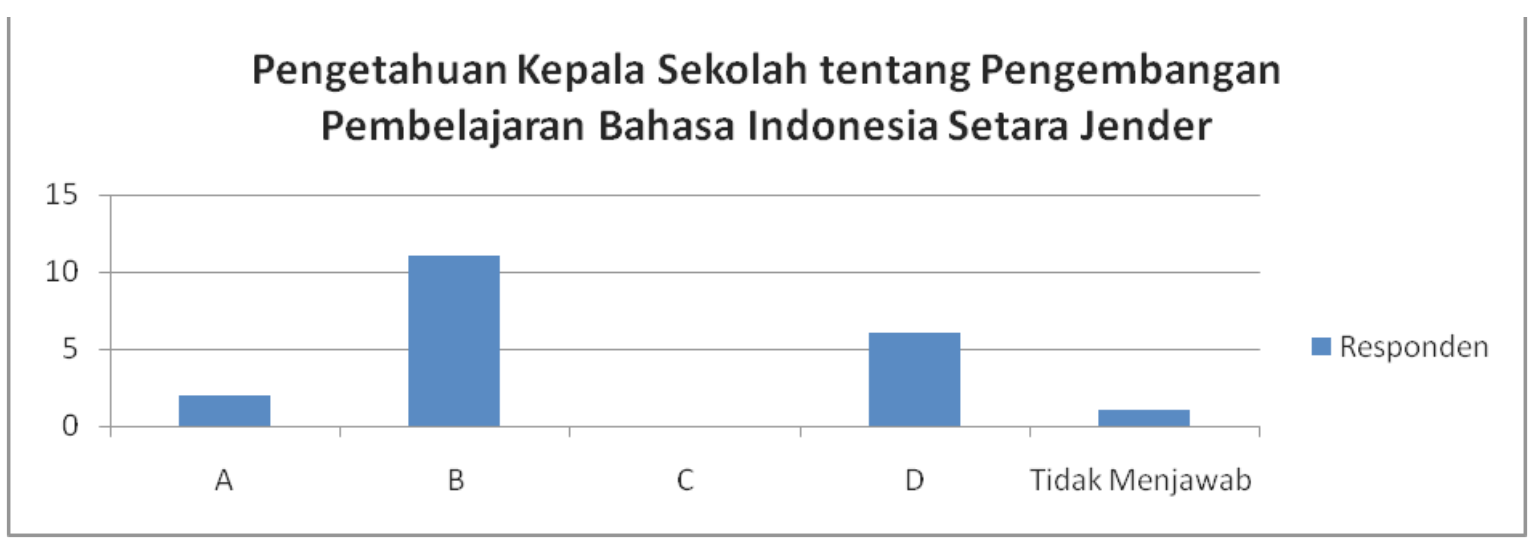

Tabel 3. Pengetahuan kepala sekolah tentang pengembangan pembelajaran Bahasa Indonesia setara jender

Selain kepala sekolah, guru juga banyak yang tidak mengetahui tentang pengembangan kurikulum bahasa Indonesia setara jender. Sebagaimana dapat dilihat pada hasil analisis, 55\% dari responden sudah mengetahui pernyataan "kurikulum bahasa Indonesia harus ditujukan untuk pengembangan peserta didik agar mengenal dirinya sebagai individu yang berbeda dengan indi- vidu lain" terdapat dalam acuan operasional pengembangan kurikulum. Sedangkan 35\% dari responden, belum mengetahui bahwa pernyataan tersebut terdapat dalam acuan operasional pengembangan kurikulum.10\% dari responden tidak menjawab. Gambaran umum dari analisis data di atas dapat dilihat pada tabel berikut. 


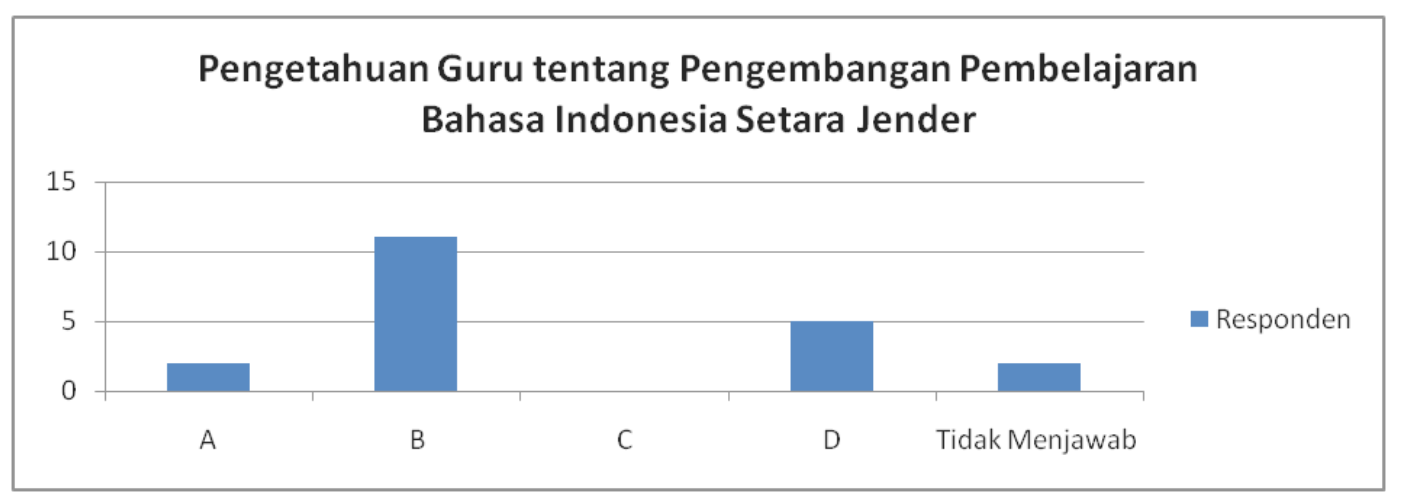

Tabel 4. Pengetahuan guru tentang pengembangan pembelajaran Bahasa Indonesia setara jender

\subsection{Pemahaman Sekolah terhadap Rat-} ifikasi Kesepakatan Internasional Indonesia tentang Jender

Kesetaraan jender merupakan program internasional yang harus didukung oleh semua negara, salah satunya adalah Indonesia. Salah satu bentuk keterlibatan Indonesia dalam program kesetaraan jender yaitu dibuatnya ratifikasi kesepakat internasional oleh Indonesia. Dalam ratifikasi tersebut dinyatakan bahwa Indonesia (a) menjamin bahwa menjelang tahun 2015 semua anak, khususnya anak perempuan, anakanak dalam keadaan yang sulit dan mereka yang termasuk etnis minoritas, mempunyai akses pada dan menyelesaikan pendidikan dasar yang bebas dan wajib dengan kualitas yang baik, (b) mencapai perbaikan 50\% pada tingkat keniraksaan orang dewasa menjelang tahun 2015, terutama bagi kaum wanita, dan akses yang adil pada pendidikan dasar dan pendidikan berkelanjutan bagi semua orang dewasa, dan (c) penghapusan kesenjangan jender pada pendidikan dasar dan menengah pada tahun 2005 dan mencapai kesetaraan jender dalam pendidikan tahun 2015 dengan fokus pada kepastian sesungguhnya bagi anak perempuan terhadap akses dalam memperoleh pendidikan dasar yang bermutu.

Ratifikasi di atas berimplikasi pada besarnya tanggung jawab Indonesia terhadap pendidikan setara jender, khususnya di Indonesia. Besarnya tanggung jawab tersebut tidak diimbangi dengan besarnya tanggung jawab sekolah melalui penyelenggaraan pendidikan setara jender. Hal itu dikarenakan banyaknya pendidik yang tidak mengetahui ratifikasi tersebut.

Dari hasil analisisi diperoleh gambaran bahwa $70 \%$ dari kepala sekolah mengetahui isi ratifikasi kesepakatan international yang dibuat Indonesia, 25\% lainnya hanya mengetahui sebagian dari isi ratifikasi tersebut, dan 5\% dari responden tidak menjawab. Gambaran analisis data di atas dapat dilihat pada tabel berikut.

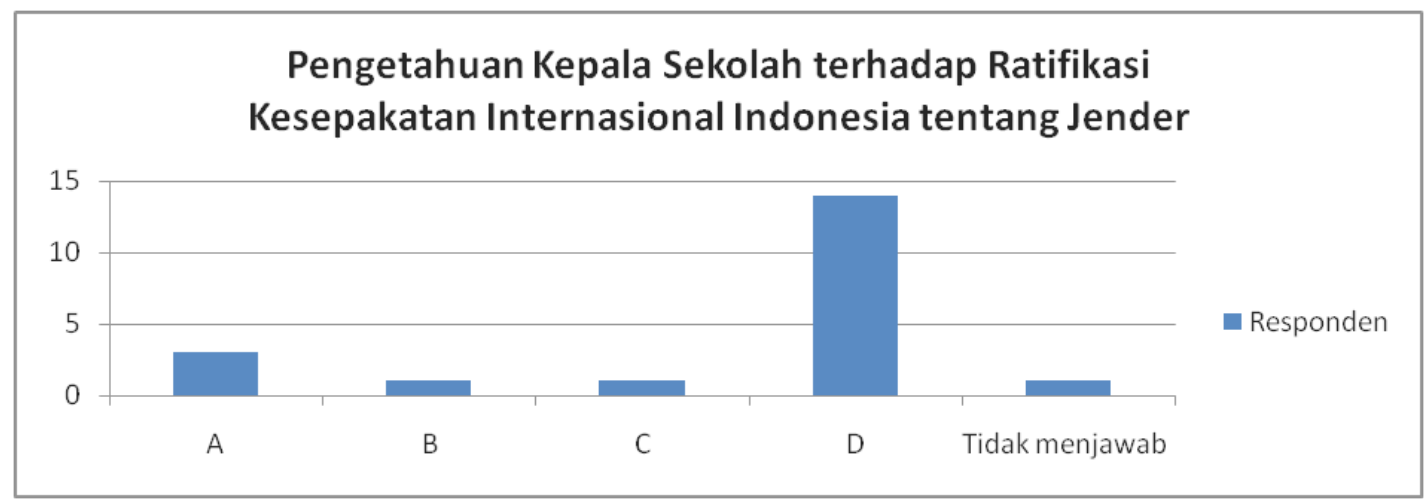

Tabel 5. Pengetahuan kepala sekolah terhadap ratifikasi kesepakatan internasional Indonesia tentang jender 
Sedangkan dari pihak guru diperoleh gambaran sebagai berikut. $70 \%$ guru mengetahui bahwa isi ratifikasi kesepakatan international yang dibuat Indonesia. Sedangkan $20 \%$ lainnya hanya mengetahui sebagian dari isi ratifikasi tersebut dan 10\% dari responden tidak menjawab. Gambaran umum dari analisis data di atas dapat dilihat pada tabel berikut.

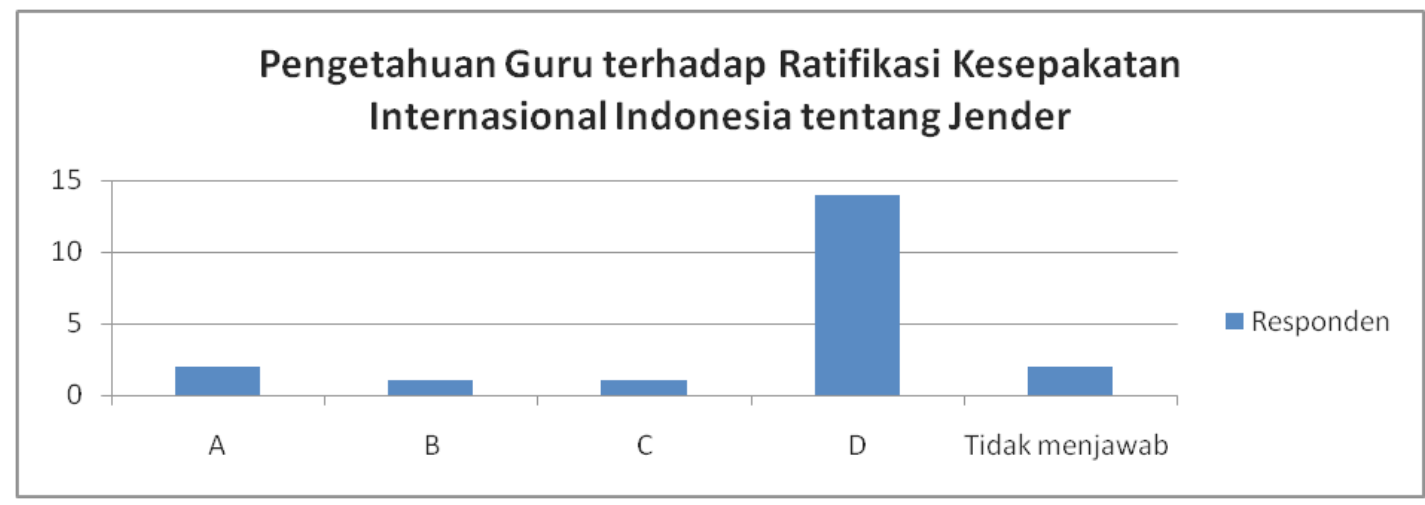

Tabel 6. Pengetahuan guru terhadap ratifikasi kesepakatan internasional Indonesia tentang jender

\section{Simpulan}

Berdasarkan hasil analisis data dapat disimpulkan bahwa sekolah kurang memahami dasar kebijakan pengembangan kurikulum setara jender. Belum semua guru dan kepala sekolah mengetahui UU No. 20 tahun 2003 tentang Sisdiknas yang berkaitan dengan penyelenggaraan pendidikan setara jender, acuan operasional pengembangan kurikulum yang berkaitan dengan pembelajaran bahasa Indonesia untuk pengenalan diri sembagai individu yang berbeda, dan ratifikasi internasional yang dibuat Indonesia tentang pengimplementasian kesetaraan jender pada pendidikan dasar.

Dari hasil penelitian ini disarankan kepada sekolah, guru, dan dosen bahasa Indonesia agar temuan penelitian hendaknya dapat digunakan sebagai bahan masukan untuk merancang kurikulum yang bisa menghargai perbedaan individual sehingga terhindar konflik akibat perbedaan jenis kelamin dan peran laki-laki dan perempuan di arena publik. Persoalan anak didik yang bersifat plural harus bisa diatasi dengan melalui pendidikan multikultural. Dalam proses pembelajaran, guru harus bisa menciptakan situasi multiarah dan dialogis sehingga memperbesar peluang setiap peserta didik untuk mengaktualisasikan diri masing-masing.

\section{Daftar Pustaka}

Agustian, G.A. 2008. Rahasia Sukses Membangun Kecerdasan Emosi dan Spiritual: ESQ. Jakarta: Penerbit Arga.

Alcoff, Linda Martin (ed.). 2003. Identities: Race, Class, Gender, and Nationality. Oxford: Blackwell.

Arikunto, S. 2002. Prosedur Penelitian; Suatu Pendekatan Praktik. Jakarta: Rineka Cipta.

Balitbang. 2003. Pelaksanaan Kurikulum Berbasis Kompetensi. Jakarta: Departemen Pendidikan Nasional. 
Bogdan, R. C dan Biklen, S. K. 1998. Qualitative Research in Education: An Introduction to Theory and Method. USA: Allyn Bacon.

Bork, W.K. \& Gall, M.D. 2003.Educational Research. White Plains: Longman Inc.

BSNP.2006. Panduan Penyusunan Kurikulum Tingkat Satuan Pendidikan Jenjang Pendidikan Dasar dan Menengah. Jakarta: Departemen Pendidikan Nasional.

Burbules, Nicholas C. 1994. Education, Discourse, and The Construction of Identity. http:// www.ed.uiuc.edu/EPS/PES-yearbook/94 docs/ BURBULES. HTM

Castells, Manuel. 2004. The Power of Identity (New Edition). Oxford: Blackwell.

Corebima. AD. 2007. Asesmen Autentik. Malang: Badan Penyelenggara Sertifikasi Guru (BPSG) Rayon 15 Universitas Negeri Malang.

Direktorat Ketenagaan, Direktorat Jenderal Pendidikan Tinggi, Departemen Pendidikan Nasional. 2006. Makalah Pelatihan Metodologi: Penelitian untuk Peningkatan Mutu (PPKP) dan Penelitian Tindakan Kelas (PTK). Padang, 5-9 April 2006.

Depdiknas. 2002. Pendekatan Kontekstual : Contextual Teaching and Learning. Jakarta: Direktorat PLP.

Dyson P, L. 2003. Identitas Etnik dan Perubahan Kebudayaan: Kasus Pada Orang Dayak di Kalimantan Teamur, Jurnal Ilmu Pengetahuan SosialVol. 4 No.I Januari 2003.

Dyson P, L. 2005. Menjadi Orang Indonesia dalam Semangat Otonomi Daerah di Tengah Arus Globalisasi. Pidato pada Pengukuhan Jabatan Guru Besar: Universitas Airlangga.

Goffman, E. 1959.The Presentation of Self In Everyday Life. New York: Doubleday Anchor.

Hamalik, O. 1995. Kurikulum Dan Pembelajaran. Jakarta: Bumi Aksara.

Ibrahim, A.S. 2008. Konstruksi Identitas Jender dalam Pertarungan Simbolik di Media Massa. Penelitian Fundamental I. Malang: Universitas Negeri Malang.

Ibrahim, A.S. 2009. Interaksi Sosial dalam Ekspresi Bahasa Jender:Kajian Harmoni Sosial dalam Perspektif Hermeneutik. Penelitian Strategi Nasional I. Malang: Universitas Negeri Malang.

Ibrahim, A.S. 2010. Interaksi Sosial dalam Ekspresi Bahasa Jender:Kajian Harmoni Sosial dalam Perspektif Hermeneutik. Penelitian Strategi Nasional II. Malang: Universitas Negeri Malang.

Kirk, S. H. 2003. Negotiating Identities Across Cultures: Migration, gender, Asylum. http:// www.iatis.org/content/korea/print korea.htm

Mato, Daniel. 2003. On the Making of Transnational Identities in the Age of Glabalization: The US Latina/o-"Latin" American Case, Identities: Race, Class, Gender, and Nationality, edited by Linda Martin Alcoff and Eduardo Mendieta. Blacwell: USA

Mudjianto. 2009. Konstruksi Identitas Jender dalam Pertarungan Simbolik di Media Massa. Penelitian Fundamental II. Malang: Universitas Negeri Malang.

Mulyasa, E. 2007. Kurikulum Tingkat Satuan Pendidikan. Bandung: PT. Remaja Rosdakarya Offset.

Mulyasa, E. 2008. Implementasi Kurikulum Tingkat Satuan Pendidikan Kemandirian Guru dan Kepala Sekolah. Jakarta: Bumi Aksara.

Mustaji \& Sugiarso. 2005. Pembelajaran Berbasis Konstruktivistik: Penerapan dalam Pembelajaran Berbasis Masalah. Surabaay: Unesa University Press. 
Nasution, S. 2008. Asas - Asas Kurikulum. Jakarta: Bumi Aksara.

Nuraini, Yuliana, dkk. 2003. Strategi Pembelajaran. Jakarta: Pusat Penerbitan Universitas Negeri Malang.

O’neil, W.F. 2002. Ideologi-ideologi Pendidikan. Yogyakarta: Pustaka Pelajar.

Panen, P. 2004. Belajar dan Pembelajaran 1. Jakarta: Pusat Penerbitan Universitas Negeri Malang.

Peraturan Menteri Pendidikan Nasional No. 22 Tahun 2006 tentang Standar Isi untuk Satuan Pendidikan Dasar dan Menengah. Jakarta: Depdiknas.

Puspitawati, H. 2011. Satuan Pendidikan Berwawasan Jender. http://pkbmcibanggala.blogspot.com/2011/12/satuan-pendidikan-berwawasan-gender.html

Rohmadi, N dan Supriono. 2000. Pemanfaatan Lingkungan Sekitar sebagai Sumber Belajar dan Pembelajaran Demokrasi dengan Menggunakan Pendekatan Cooperatif Learning. Hasil Penelitian. Malang: Lembaga Penelitian UM.

Ruminiati, dkk. 2007. Program Hibah Kemitraan Peningkatan Jalinan Informasi dengan Diknas: Pemetaan dan Penyediaan Kebutuhan Guru. Malang: Jurusan Kependidikan Sekolah Dasar dan Prasekolah, Fakultas Ilmu Pendidikan, Universitas Negeri Malang.

Suyanto, K.K.E. 2003. Pembelajaran Berbasis CTL (Contextual Teaching and Learning). Makalah disajikan dalam Sarasehan Pendekatan Pembelajaran Kontekstual di Fakultas Sastra Universitas Negeri Malang, 7-8 Maret.

2007. Pendekatan, Metode, dan Teknik. Malang: Badan Penyelenggara Sertifikasi Guru (BPSG) Rayon 15 Universitas Negeri Malang. http://www.depdiknas.go.id/RPP/ modules.php? name $=$ News \&file $=$ article $\&$ sid $=28$.

Tampubolon, D. P. 2001. Perguruan Tinggi Bermutu. Paradigma Baru Manajemen Pendidikan Tinggi Menghadapi Tantangan Abad ke-21. Jakarta: Penerbit Gramedia Pustaka Utama.

Trihendradi, C. 2007. Langkah Mudah Menguasai Statistik Menggunakan SPSS 15. Yogyakarta: Andi Offset.

Undang-undang Republik Indonesia No. 20 Tahun 2003 Tentang Sistem Pendidikan Nasional. Bandung: Citra Umbara.

Pusat Kurikulum, Badan Penelitian dan Pengembangan. 2002. Kurikulum dan Hasil Belajar: Rumpun Pelajaran Bahasa Indonesia. Jakarta: Badan Penelitian dan Pengembangan.

............... 2002. Ringkasan Kegiatan Belajar Mengajar. Jakarta: Badan Penelitian dan Pengembangan.

2002. Ringkasan Kurikulum Berbasis Kompetensi. Jakarta: Badan Penelitian dan Pengembangan.

Silverman, D. 1995. Interpreting Qualitative Data: Methods for Analysing Talk, Text, dan Interaction. New Delhi: Sage Publications

Wahyuni, L. 2007. Representasi Jender dalam Wacana Anti Pornografi dan Pornoaksi. Penelitian Dosen Muda. Malang: IKIP Budi Utomo

Zein, M. 1991. Asas dan Pengembangan Kurikulum. Yogyakarta: Sumbangsih Offset. 